\title{
Independent Sources of Quantal Variability at Single Glutamatergic Synapses
}

\author{
Kevin M. Franks, ${ }^{1,2,4}$ Charles F. Stevens, ${ }^{1,3}$ and Terrence J. Sejnowski ${ }^{1,2,4}$ \\ ${ }^{1}$ Howard Hughes Medical Institute, ${ }^{2}$ Computational and ${ }^{3}$ Molecular Neurobiology Laboratories, The Salk Institute for Biological Studies, La Jolla, California \\ 92037, and ${ }^{4}$ Division of Biology, University of California, San Diego, La Jolla, California 92093
}

\begin{abstract}
Variability in the size of single postsynaptic responses is a feature of most central neurons, although the source of this variability is not completely understood. The dominant source of variability could be either intersynaptic or intrasynaptic. To quantitatively examine this question, a biophysically realistic model of an idealized central axospinous synapse was used to assess mechanisms underlying synaptic variability measurements. Three independent sources of variability were considered: stochasticity of postsynaptic receptors ("channel noise"), variations of glutamate concentration in the synaptic cleft $(\Delta q)$, and differences in the potency of vesicles released from different locations on the active zone [release-location dependence (RLD)]. As expected, channel noise was small ( $8 \%$ of the total variance) and $\Delta q$ was the dominant source of variability ( $58 \%$ of total variance). Surprisingly, RLD accounted for a significant amount of variability (36\%). Our simulations show that potency of release sites decreased with a length constant of $\sim 100 \mathrm{~nm}$, and that receptors were not activated by release events $>300 \mathrm{~nm}$ away, which is consistent with the observation that single active zones are rarely $>300 \mathrm{~nm}$. RLD also predicts that the manner in which receptors are added or removed from synapses can dramatically affect the nature of the synaptic response, with increasing receptor density being more efficient than merely increasing synaptic area. Saturation levels and synaptic geometry were also important in determining the size and shape of the distribution of amplitudes recorded at different synapses.
\end{abstract}

Key words: synaptic variability; glutamate concentration; saturation; synaptic geometry; computational model; Monte Carlo methods

\section{Introduction}

Large variability in the size of miniature postsynaptic potentials or currents (called "minis") occurs in most if not all central synapses. Mini amplitudes recorded from single neurons typically have highly skewed distributions and coefficients of variation $(\mathrm{CV})$ of $\sim 0.5$. If the variability measured at single synapses is small relative to that of the entire cell, then most of the variability must be attributable to potency differences between synapses. However, if the mini distributions measured at individual sites are similar to that of the entire population, most of the variability must originate at individual synapses. Whether mini variability is intersynaptic or intrasynaptic has not yet been definitively answered (for review, see Auger and Marty, 2000). Some studies report highly variable, skewed distributions of mini amplitudes recorded at single synapses that suggest that the majority of the variability originates within individual synapses (Bekkers et al., 1990; Raastad et al., 1992; Frerking et al., 1995; Liu and Tsien, 1995; Liu et al., 1999; McAllister and Stevens, 2000). However, others have found mini amplitudes at single synapses to be less variable and have Gaussian distributions (Tang et al., 1994; Bolshakov and Siegelbaum, 1995; Silver et al., 1996; Auger and Marty, 1997; Forti et al., 1997). Finally, a recent report using

Received Nov. 14, 2002; revised Jan. 21, 2003; accepted Jan. 22, 2003.

This work was supported by the Howard Hughes Medical Institute and the National Science Foundation. We thank Thomas Bartol for technical assistance and Jeffry Isaacson and Richard Weinberg for reading a previous version of this manuscript.

Correspondence should be addressed to Terrence J. Sejnowski, Computational Neurobiology Laboratory, The Salk Institute, 10010 North Torrey Pines Road, La Jolla, CA 92037. E-mail: terry@salk.edu.

K. M. Franks's present address: Department of Neurosciences, University of California, School of Medicine, La Jolla, CA 92093.

Copyright $\odot 2003$ Society for Neuroscience $\quad 0270-6474 / 03 / 233186-10 \$ 15.00 / 0$ minimal stimulation of hippocampal CA3-CA1 synapses found variability in synaptic variability, with both skewed highvariability synapses and Gaussian low-variability synapses in the same preparation (Hanse and Gustafsson, 2001).

Three sources of variability in mini amplitude at single synapses are proposed. The first source of variability is stochastic fluctuations in the number of activated postsynaptic receptors and in their open times (Faber et al., 1992; Franks et al., 2002). Presynaptic factors could also contribute to quantal variability, but only if the receptors are not saturated by the release of a single vesicle. Indeed, recent experiments and models suggest that neither AMPA receptors (AMPARs) nor NMDA receptors (NMDARs) are saturated after quantal release (Holmes, 1995; Liu et al., 1999; Mainen et al., 1999; McAllister and Stevens, 2000; Franks et al., 2002; Ishikawa et al., 2002). Although presynaptic release resulted in highly variable, skewed distributions of mini amplitudes, focal iontophoretic glutamate application in which the quantal size $(q)$ can be assumed to be nearly constant evoked currents with little variability and Gaussian distributions (Liu et al., 1999; McAllister and Stevens, 2000), suggesting that variations in the quantal content of single vesicles $(\Delta q)$ account for much of the observed variability (Bekkers et al., 1990; Frerking et al., 1995; Liu et al., 1999; Hanse and Gustafsson, 2001). This is the second main source proposed for mini variability.

Hippocampal neuron active zones are closely aligned with the postsynaptic density (PSD) and typically contain $\sim 10$ readily releasable vesicles distributed across the entire active zone (Dobrunz and Stevens, 1997; Schikorski and Stevens, 1997, 2001; Murthy et al., 2001). Single action potentials release, at most, a single vesicle (Stevens and Wang, 1995; Hanse and Gustafsson, 2001) from one of these locations (but see Oertner et al., 2002). 
Therefore, if glutamate equilibrates nearly instantaneously along the cleft, all release sites should be equally potent. However, if sizeable neurotransmitter concentration gradients extend across the synapse from the site of release, then release from different locations within the active zone will have different potencies (Uteshev and Pennefather, 1996, 1997). Thus, the third potential source of synaptic variability is the release from different sites on the active zone, which we call release-location dependence (RLD).

Using a biophysically realistic Monte Carlo simulation, we show here that variability at single synapses can be large enough to account for observed mini distributions and present plausible mechanistic explanations for the differences in the size and shape of different observations.

\section{Materials and Methods}

Monte Carlo algorithms for modeling synaptic transmission have been described and verified previously (Bartol et al., 1991; Stiles and Bartol, 2001; Stiles et al., 2001). Molecular glutamate diffusion was modeled using a three-dimensional random walk. A fixed time step of $1 \mu \mathrm{sec}$ was used throughout this study. Individual unimolecular or bimolecular kinetic interactions were handled probabilistically on the basis of macroscopic rate constants. The primary simulation output used was the time series of receptor states, including the open-conducting state (see below). Voltage-clamp conditions are therefore assumed such that the number of open AMPARs scales directly with the AMPA postsynaptic current. Rate constants were derived from experiments conducted at room temperature, which we therefore assume for all simulations. Simulations were run on a cluster of $933 \mathrm{MHz}$ personal computer workstations running FreeBSD 4.2. It took $\sim 2 \mathrm{~min}$ to simulate $1 \mathrm{sec}$ of real time. Threedimensional images of MCell output were rendered with IBM Data Explorer (available at http://www.opendx.org) using custom written software (DReAMM; Joel Stiles, University of Pittsburgh, Pittsburgh, PA; available at http://www.mcell.psc.edu/DReAMM). Data are presented as mean \pm SD.

Synaptic and extrasynaptic geometries. The presynaptic bouton and postsynaptic spine were modeled as two cubes, $0.5 \mu \mathrm{m}$ on a side, and separated by a $20 \mathrm{~nm}$ synaptic cleft. The spine was connected to a $1 \times 1 \times$ $4 \mu \mathrm{m}$ shaft of dendrite by a $0.5-\mu \mathrm{m}$-long spine neck $(0.2 \times 0.2 \mu \mathrm{m}$ in cross section). The neuropil was $4 \times 4 \times 4 \mu \mathrm{m}$, which was built around these structures, composed of cuboidal elements ( $0.5 \mu \mathrm{m}$ on a side), and packed together with a $20 \mathrm{~nm}$ gap of extracellular space surrounding each element (Franks et al., 2002).

Channel kinetic parameters. Unless stated otherwise, AMPARs were uniformly distributed at specified densities on the PSD (a 350-nmdiameter disk-shaped structure on the synaptic face of the postsynaptic spine). AMPARs were modeled using the reaction scheme and kinetic rate constants from Jonas et al. (1993) as follws:

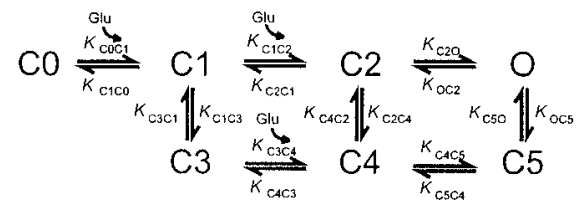

Here, $\mathrm{C} 0$ is the unbound AMPAR; $\mathrm{C} 1$ is the single-bound receptor intermediate; $\mathrm{C} 2$ and $\mathrm{O}$ are the double-bound closed- and open-conducting channel conformations, respectively; and C3, C4, and C5 are desensitized states. $K_{\mathrm{XY}}$ is the kinetic rate for the transition from state $X$ to state $Y$ : $K_{\mathrm{COC} 1}, 4.59 \times 10^{6} \mathrm{M}^{-1} \mathrm{sec}^{-1} ; K_{\mathrm{C} 1 \mathrm{C} 0}, 4.26 \times 10^{3} \mathrm{sec}^{-1} ; K_{\mathrm{C} 1 \mathrm{C} 2}, 2.84 \times 10^{7}$ $\mathrm{M}^{-1} \mathrm{sec}^{-1} ; K_{\mathrm{C} 2 \mathrm{C} 1}, 3.26 \times 10^{3} \mathrm{sec}^{-1} ; K_{\mathrm{C} 2 \mathrm{O}}, 4.24 \times 10^{3} \mathrm{sec}^{-1} ; K_{\mathrm{OC} 2}, 900$ $\mathrm{sec}^{-1} ; K_{\mathrm{C} 1 \mathrm{C} 3}, 2.89 \times 10^{3} \mathrm{sec}^{-1} ; K_{\mathrm{C} 3 \mathrm{C} 1}, 39.2 \mathrm{sec}^{-1} ; K_{\mathrm{C} 3 \mathrm{C} 4}, 1.27 \times 10^{6}$ $\mathrm{M}^{-1} \mathrm{sec}^{-1} ; K_{\mathrm{C} 4 \mathrm{C} 3}, 45.7 \mathrm{sec}^{-1} ; K_{\mathrm{C} 2 \mathrm{C} 4}, 172 \mathrm{sec}^{-1} ; K_{\mathrm{C} 4 \mathrm{C} 2}, 0.727 \mathrm{sec}^{-1}$; $K_{\mathrm{C} 4 \mathrm{C} 5}, 16.8 \mathrm{sec}^{-1} ; K_{\mathrm{C} 5 \mathrm{C} 4}, 190.4 \mathrm{sec}^{-1} ; K_{\mathrm{OC} 5}, 17.7 \mathrm{sec}^{-1}$; and $K_{\mathrm{C} 5 \mathrm{O}}, 4$ $\sec ^{-1}$.

NMDA receptors were modeled using the reaction scheme and kinetic rate constants from Lester and Jahr (1992) and Jonas et al. (1993) as follows:

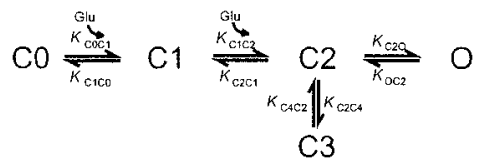

The nomenclature for rate constants is the same as that with which AMPARs were modeled: $K_{\mathrm{COC} 1}, 1 \times 10^{7} \mathrm{M}^{-1} \mathrm{sec}^{-1} ; K_{\mathrm{C} 1 \mathrm{CO} 0}, 4.7 \mathrm{sec}^{-1} ; K_{\mathrm{C} 1 \mathrm{C} 2}$, $5 \times 10^{6} \mathrm{M}^{-1} \mathrm{sec}^{-1} ; K_{\mathrm{C} 2 \mathrm{C} 1}, 9.4 \mathrm{sec}^{-1} ; K_{\mathrm{C} 2 \mathrm{O}}, 46.5 \mathrm{sec}^{-1} ; K_{\mathrm{OC} 2}, 91.6 \mathrm{sec}^{-1}$; $K_{\mathrm{C} 2 \mathrm{C} 3}, 8.4 \mathrm{sec}^{-1}$; and $K_{\mathrm{C} 3 \mathrm{C} 2}, 1.8 \mathrm{sec}^{-1}$. There was no voltage-dependent block of NMDARs, assuming conditions of $0 \mathrm{Mg}^{2+}$.

Astroglial glutamate transporters (GluTs) are likely widely and uniformly distributed throughout the neuropil (Bushong et al., 2002) at densities $\sim 1000-2000 \mu \mathrm{m}^{-2}$ (Takahashi et al., 1996; Lehre and Danbolt, 1998). We have shown that AMPAR activation is insensitive to the degree of uptake (Franks et al., 2002), which is consistent with experimental observations (Isaacson and Nicoll, 1993; Sarantis et al., 1993). For computational expediency, we therefore placed GluTs on all neuropil elements at a density of $10,000 \mu \mathrm{m}^{-2}$. A simple three-state mechanism was used for all transporters, as follows:

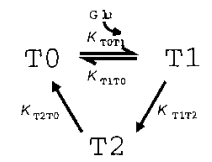

where $\mathrm{T} 0$ and $\mathrm{T} 1$ are the unbound- and bound-transporter states, respectively, and T2 is an intermediate state in which the bound glutamate is removed from the simulation. The kinetic rates were as follows: $K_{\mathrm{TOT} 1}$, $1.80 \times 10^{7} \mathrm{M}^{-1} \mathrm{sec}^{-1} ; K_{\mathrm{T} 1 \mathrm{TT} 0}, 180 \mathrm{sec}^{-1} ; K_{\mathrm{T} 1 \mathrm{~T} 2}, 180 \mathrm{sec}^{-1}$; and $K_{\mathrm{T} 2 \mathrm{~T} 0}$, $25.7 \mathrm{sec}^{-1}$ (Geiger et al., 1999).

Glutamate release. Glutamate was instantaneously released as a point source in the synaptic cleft. In some simulations, a transmitter was always released from the center of the cleft. In other simulations, a specified number of release locations were randomly assigned on a plane of specified area that was parallel to and just below the presynaptic bouton. $D_{\mathrm{Glu}}$ was $0.2 \mu \mathrm{m}^{2} / \mathrm{msec}$ unless otherwise stated. In one set of simulations, glutamate was released by assuming diffusion of 2000 molecules through a fusion pore. The pore ( $9 \mathrm{~nm}$ in length) connected a vesicle with a diameter of $35 \mathrm{~nm}$ and the cleft, and expanded at a rate of $25 \mathrm{~nm} \cdot \mathrm{msec}^{-1}$ (Stiles et al., 1996).

Quantal amplitude distribution. Multiple simulations ( $n$ ) were performed for each condition to obtain a histogram for the number of quantal events with a given peak amplitude. The mean $(m)$ and $\mathrm{SD}(\sigma)$ of each distribution were computed along with its skewness and defined as follows:

$$
\gamma=\frac{\mu_{3}}{\sigma^{3}}
$$

where $\mu_{3}$ is the third-order moment of the distribution about the mean.

\section{Results}

To determine quantitatively the relative contributions of these three sources of synaptic variability ("channel noise," $\Delta q$, and RLD), we have used a Monte Carlo simulation environment to simulate the activation of postsynaptic AMPA receptors after the release of a quantum of transmitter. Our simulations followed individual glutamate molecules as they diffused through a spatially complex three-dimensional neuropil. Glutamate was released instantaneously from a point source in the synaptic cleft, which is the volume defined by the $20 \mathrm{~nm}$ separation between the synaptic faces of the presynaptic bouton and the postsynaptic spine. Synaptic glutamate concentrations decayed rapidly because of diffusion of the cleft and uptake by GluTs distributed across the extrasynaptic membrane surfaces of the neuropil, whereas in the synaptic cleft, glutamate could bind to and activate 


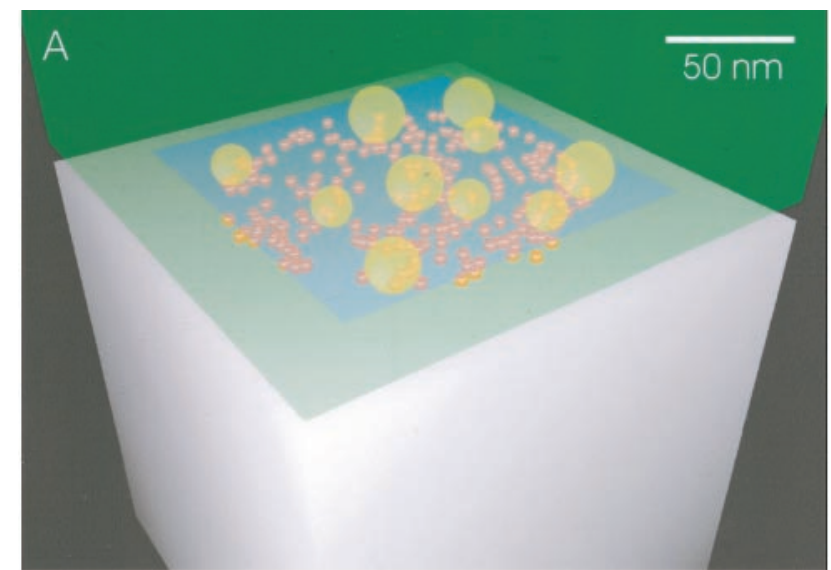

$\mathrm{Bi}$

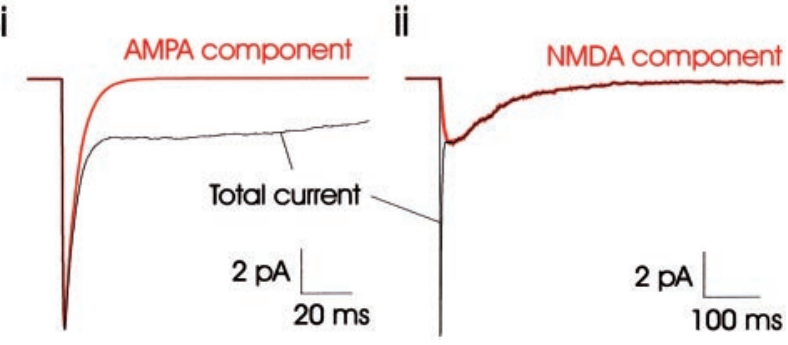

Figure 1. Simulated miniature EPSCs (mEPSCs) are composed of AMPA and NMDA components. $A$, AMPA and NMDA receptors (red icons) were distributed on the top surface of a spine head (gray cube). A presynaptic bouton (green) was separated from the spine by a $20 \mathrm{~nm}$ synaptic cleft. Synaptic vesicles (yellow) were randomly assigned above the PSD, on a surface adjacent to the bottom of the PSD (blue). This structure was embedded within a complex three-dimensional tortuous neuropil (not shown). B, Ensemble miniature EPSCs (black) showing the AMPA ( $i$ ) and NMDA (ii) components (red).

postsynaptic receptors. These results, and a full description of the model, have been published previously (Franks et al., 2002).

We simulated the activation of a round PSD (350 nm diameter) populated with $\sim 200$ AMPARs and 20 NMDARs after quantal release, either from the center of the active zone or one of 10 randomly assigned release locations on a $350 \times 350 \mathrm{~nm}$ plane just adjacent to the bouton (Fig. $1 A$ ). Vesicle-lumen diameters were selected from a normal distribution $\left(\bar{x}=25 \mathrm{~nm} ; \sigma_{\mathrm{v}}=3.4 \mathrm{~nm}\right)$ (Schikorski and Stevens, 1997) and filled to a constant concentration of $0.406 \mathrm{M}$ (Karunanithi et al., 2002), such that a vesicle with a lumen diameter of $25 \mathrm{~nm}$ contained exactly 2000 glutamate molecules. Ensemble-averaged $(n=1000)$ EPSCs were simulated by scaling the number of open receptors by their singlechannel conductance (AMPA, $10 \mathrm{pS}$; NMDA, $45 \mathrm{pS}$ ) and a driving force of $-65 \mathrm{mV}$, and summing the AMPA and NMDA components. The resulting EPSC had a large rapid phase mediated primarily $(>98 \%)$ by the AMPAR component (Fig. $1 \mathrm{Bi}$ ), which had a $20-80 \%$ rise time of $90 \mu \mathrm{sec}$, a rapid decay that could be fit with a single exponential $(\tau, 2.6 \mathrm{msec})$. The smaller slow component of the EPSC was attributable to the NMDA component (Fig. 1 Bii).

Synaptic variability distributions typically describe the maximum of the EPSC current; thus, for simplicity, we equate mini amplitude with the peak number of open AMPARs and henceforth do not explicitly consider the NMDAR-mediated component of the EPSC. Figure $2 A$ shows the high variability in the number of open AMPARs after transmitter release in four typical trials. Peak mini amplitude was defined as the greatest number of channels in the open state during that trial. An average $\left(\bar{x}_{\mathrm{AMPA}}\right)$ of
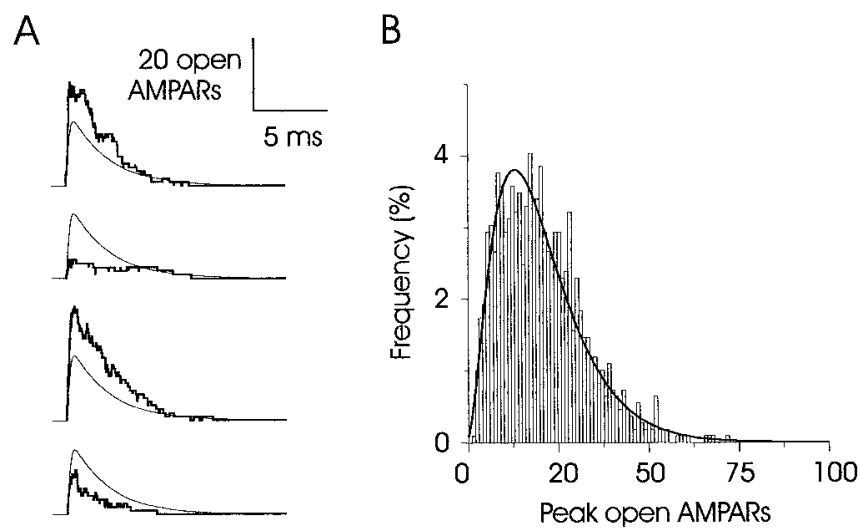

Figure 2. Distribution of synaptic amplitudes at a single synapse. $A$, Typical individual traces (thick traces) plotted with the ensemble average (thin traces; 1100 simulations averaged together). $B$, Normalized distribution of peaks from all 1000 simulations ( 100 from each of the 11 release locations). The solid line is a theoretical fit to the data using Equation 2 ( $r=0.977$ ).

20 AMPARs opened at peak, with an SD $\left(\sigma_{\text {AMPA }}\right)$ of $12(\mathrm{CV}$, 0.58 ). The distribution of peak amplitudes (Fig. $2 B$ ) was skewed from the normal (skewness, $\gamma=0.87$ ), and could be fitted using the following:

$$
P(x)=k e^{\frac{-x^{1 / 3}-m^{2 / 3}}{\left(\sigma^{2 / 3}\right)}} \cdot x^{-2 / 3}
$$

where $P(x)$ is the probability that a single trial will have an amplitude $x$, and $m$ and $\sigma$ are the mean and variance, respectively, of the peak number of open AMPARs. This relationship was first used by Bekkers et al. (1990) to fit the measured distribution of mini amplitudes based on the jitter in vesicle diameter. The number of open NMDARs was $2.1 \pm 1.5(\mathrm{CV}, 0.7)$, and the distribution had a skewness of 0.69 (data not shown). Our simulations therefore reproduce experimental measures of quantal variability. However, we specifically wanted to determine the individual contribution of the different sources of variability. Therefore, we isolated each of the three proposed sources of variability and examined them in the simulations described below.

\section{Channel noise}

We first examined the variability attributable solely to the probabilistic nature of postsynaptic receptors and to local differences in the three-dimensional distribution of transmitter molecules resulting from their random walk diffusion. These properties, which we collectively term channel noise, set an upper limit on the fidelity of the function of a synapse. Channel noise was estimated by always releasing a quantum of exactly 2000 molecules from a fixed position above the center of the PSD. Under these conditions, variability was dramatically reduced $\left(\bar{x}_{\mathrm{AMPA}}, 32\right.$; $\sigma_{\mathrm{AMPA}}, 5.2 ; \mathrm{CV}, 0.16$ ) (Fig. $3 A$ ), and the distribution of mini amplitudes was well fitted with a Gaussian distribution (Fig. 3B), consistent with experiments in which fixed amounts of glutamate were directly applied to single synapses (Liu et al., 1999; McAllister and Stevens, 2000). Repeated release of exactly 2000 glutamate molecules from the center of the synapse opened $3.0 \pm 1.36(\mathrm{CV}$, $0.47)$ NMDARs. Channel noise therefore accounts for the majority of the variability when the number of receptors is small. Other simulations have shown that channel noise decreases with increases in both quantal size and postsynaptic receptor number, and channel noise is similar for equal numbers of AMPA and NMDA receptors (Franks et al., 2002).

To determine the amount of the channel noise caused by trial- 
A
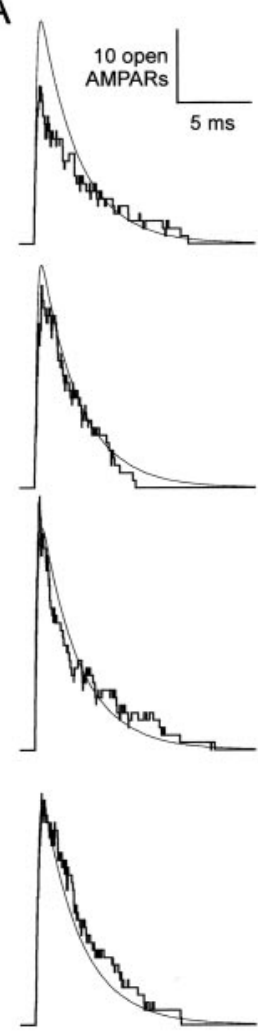
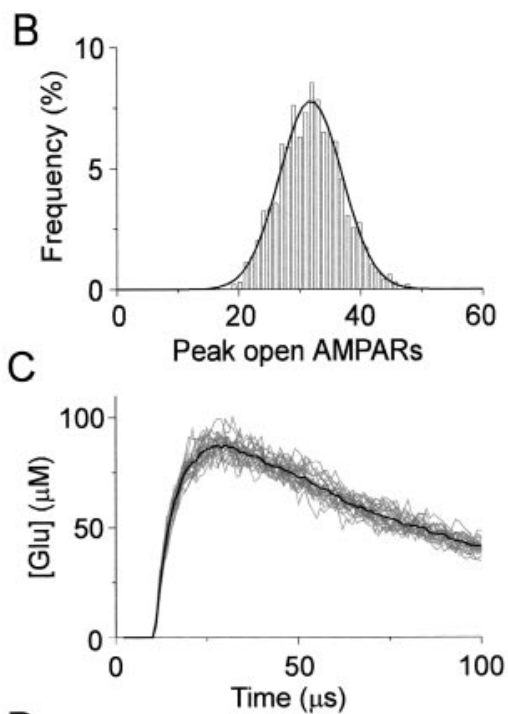

D

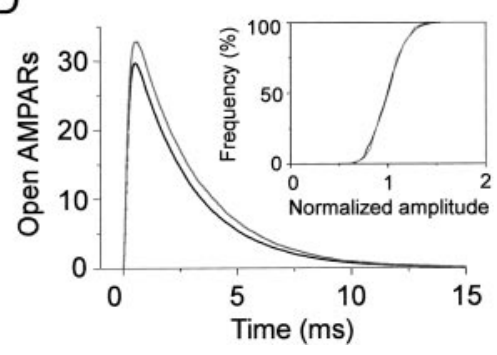

Figure 3. Noise caused by stochastic flicker of receptors. $A$, Examples of four typical individual trials. Raw traces (thick traces) are plotted with ensemble averages (thin traces; $n=1000$ ) after release of exactly 2000 glutamate molecules. B, Distribution of synaptic responses. A normal distribution could be fit to the data (solid line; $r=0.995$ ). C, Glutamate (Glu) concentration in a sampling volume within the synaptic cleft for nine trials (thin gray traces) plotted with the ensemble average of 1000 trials (thick black trace) shows little trial-to-trial variability. $D$, Ensemble average of traces with (black) and without (gray) desensitization states. Inset, Cumulative histogram of normalized amplitudes with (black) and without (gray) variability.

to-trial variations in local transmitter concentration, we measured glutamate concentration in a 0.45 al sampling volume positioned in a quadrant of the cleft. As might be expected, peak concentration within the volume showed little variability ( $91 \pm$ $4.2 \mu \mathrm{M} ; n=500$ ) (Fig. 3C), suggesting that the major source of channel noise was stochastic fluctuation between conducting and nonconducting AMPAR states. The kinetic scheme used to model AMPARs has three desensitized nonconducting states. Stochastic fluctuations between these and the open conducting state could decrease mean peak amplitude and add to channel noise. We therefore ran the simulation using a kinetic scheme that did not include any desensitized states. Indeed, removal of the desensitized states increased $\bar{x}_{\mathrm{AMPA}}$ to $35(n=500)$ but did not affect the variability $(\mathrm{CV}, 0.16)$ (Fig. $3 D$ ), suggesting that most channel noise was caused by stochastic fluctuations between the C2 (closed state) and the O (open conducting state) (see below).

A transmitter enters the synaptic cleft after the vesicle fuses with the presynaptic membrane and a fusion pore allows the passage of the transmitter into the cleft. Stiles et al. (1996) determined that transmitter escape from a vesicle could be accurately modeled with passive diffusion through a fusion pore expanding at $25 \mathrm{~nm} \cdot \mathrm{msec}^{-1}$. We compared mini variability in simulations in which glutamate was released as a bolus or as a function of time (Stiles et al., 1996). Slowing transmitter release slightly decreased
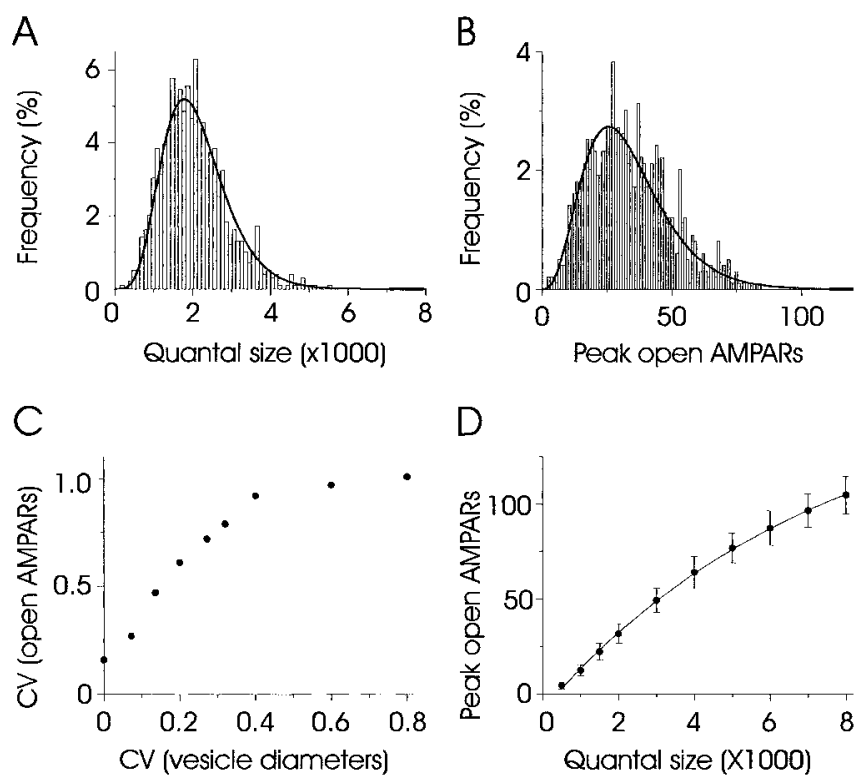

Figure 4. Variability in quantal size contributes to most synaptic variability. $A, B$, Distribution of quantal sizes $(A)$ and resulting synaptic responses with vesicle-lumen diameters set to $25 \pm 3.4 \mathrm{~nm}(B ; n=1000)$. Solid lines are forced fits of $q$ and mini amplitudes to the distribution predicted by Equation 2. C, Summary of increasing synaptic variability plotted against increasing variability in vesicle diameter. D, Dose-response curves for 200 AMPARs at a 350nm-diameter PSD. The solid line is an exponential fit to the data $N_{\text {open }}=172 \times(1-$ $\left.e^{-q / 7400}\right)-8.2$.

the peak activation of receptors but did not affect the variability (data not shown). We therefore continued to model transmitter release as an instantaneous process. Note that jitter in the opening rate of the fusion pore would increase $\sigma_{\mathrm{AMPA}}$, but investigating this issue is beyond the scope of this study. Channel noise therefore accounts for a small but significant amount of total observed variability, primarily attributable to stochastic fluctuations of double-bound receptors between the closed- and openconducting states.

\section{Dependence on quantal size}

Variability in transmitter concentration has often been assumed to be the major source of mini variability at central synapses (Bekkers et al., 1990; Frerking et al., 1995; Liu et al., 1999; McAllister and Stevens, 2000; Hanse and Gustafsson, 2001). To determine the amount of variability caused by variations in $q$, the release location was held constant at the center of the active zone, and vesicle-lumen diameters were randomly drawn from a normal distribution with a mean $\left(\bar{x}_{\mathrm{v}}\right)$ of $25 \mathrm{~nm}$ and $\mathrm{SD}\left(\sigma_{\mathrm{v}}\right)$ of $3.4 \mathrm{~nm}$. Jitter in vesicle size did not significantly affect mean quantal size $(\bar{q})$ but resulted in a wide skewed distribution (skewness, 0.82 ) of $q$ that was well fitted by Equation 2 (Fig. 4A). The resulting $\bar{x}_{\mathrm{AMPA}}, 33$, was not significantly different from release with fixed $q$, but the mini distribution was significantly more variable $(\mathrm{CV}$, $0.47 ; n=1000 ; p<10^{-10} ; f$ test (Fig. $4 B$ ). The mini amplitude distribution was also highly skewed (0.58) and could also be described by Equation 2. Increasing $\sigma_{\mathrm{v}}$ increased the variability and skewness of both $q$ and the distribution of mini amplitudes (Fig. $4 C$, Table 1 ). Note that $\bar{q}$, and therefore also $\bar{x}_{\mathrm{AMPA}}$, systematically increased with increasing $\sigma_{\mathrm{v}}$ resulting from the lower bound of no glutamate molecules in a vesicle.

The two key assumptions used in the derivation of Equation 2 were that all vesicles were filled to the same concentration (Karunanithi et al., 2002) and receptors operated on an approximate 
Table 1. Effects of varying quantal size on synaptic variability at a 350-nm-diameter PSD

\begin{tabular}{|c|c|c|c|c|c|c|c|c|}
\hline \multicolumn{2}{|c|}{ Vesicle diameter } & \multicolumn{3}{|c|}{ Quantal size } & \multicolumn{4}{|c|}{ Peak open AMPARs } \\
\hline $\bar{x}_{\mathrm{v}}$ & $\sigma_{\mathrm{v}}$ & $\bar{x}_{\mathrm{q}}$ & $\sigma_{q}$ & Skewness & $\bar{x}_{\text {AMPA }}$ & $\sigma_{\text {AMPA }}$ & $\mathrm{CV}$ & Skewness \\
\hline 25 & 0 & 2000 & 0 & & 32 & 5.2 & 0.16 & 0.14 \\
\hline 25 & 1.7 & 2017 & 404 & 0.33 & 32 & 8.8 & 0.27 & 0.35 \\
\hline 25 & 3.4 & 2089 & 828 & 0.82 & 33 & 15 & 0.47 & 0.58 \\
\hline 25 & 5 & 2204 & 1264 & 1.2 & 34 & 21 & 0.61 & 0.7 \\
\hline 25 & 6.8 & 2474 & 1874 & 1.7 & 37 & 27 & 0.72 & 0.61 \\
\hline 25 & 8 & 2649 & 2310 & 1.9 & 39 & 31 & 0.79 & 0.59 \\
\hline
\end{tabular}
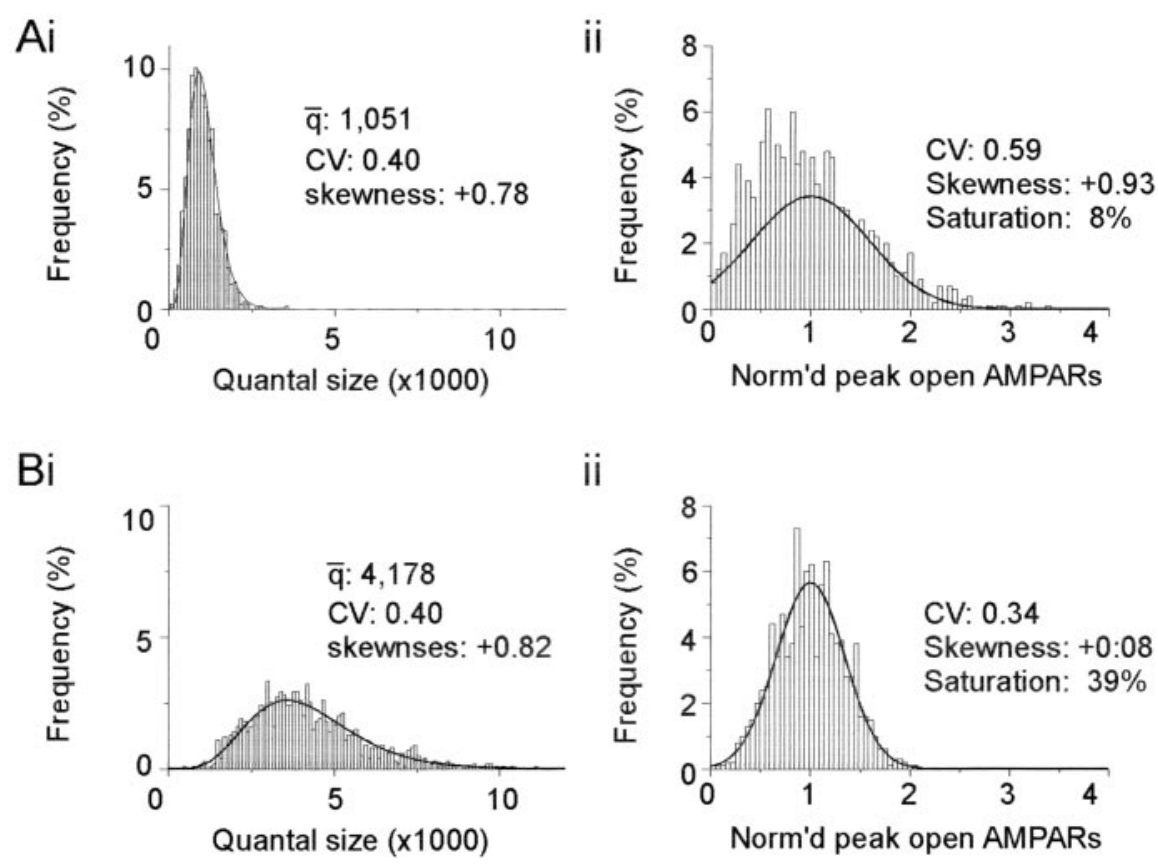

ii

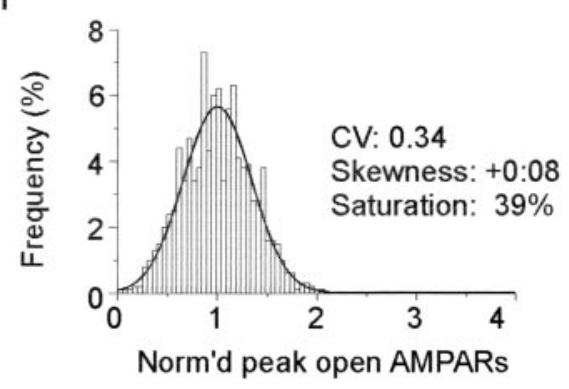

Figure 5. The shape of mini amplitude distributions depends on vesicle concentration. $A$, Distribution of $q(i)$ and peak (ii) amplitudes for vesicles with $\bar{q}=1000$ glutamate molecules. $B$, Distribution of $q$ (i) and peak (ii) amplitudes for vesicles with $\bar{q}=$ 4000 glutamate molecules. Solid lines in Ai and Bi are forced fits to Equation 2. Solid lines in Aii and Bii are Gaussian fits to the data. Note that for both cases, the shape of the input $(q)$ was the same, whereas the shape of the output (peak number of open AMPARs) was drastically different.

linear range of the dose-response curve (Bekkers et al., 1990). We have explicitly satisfied the first condition and now test the second. Although release of different-sized quanta produced a saturating nonlinear dose-response curve, the relationship was approximately linear in the range of observed $q$ in the simulations described above (Fig. 4D).

The implications of a linear versus nonlinear dose-response curve are shown in Figure 5. Two sets of simulations were run, but now with different vesicle concentrations such that $\bar{q}$ was set to either $\sim 1000$ (Fig. $5 A i$ ) or $\sim 4000$ (Fig. $5 B i$ ) and the jitter in vesicle size was the same $(25 \pm 3.4 \mathrm{~nm})$. The distributions of $q$ had similar skewness $(\sim 0.8)$ and variability $(\mathrm{CV}, 0.40)$. If the dose-response relationship of AMPARs was linear for both conditions, then the distributions of peak amplitudes should have similar shapes (i.e., same skewness and variability). Instead, we found that the distribution of amplitudes resulting from lessconcentrated vesicles was highly skewed and very variable (Fig. 5 Aii), whereas the amplitude distribution from highly concentrated vesicles was Gaussian with a low CV (Fig. 5Bii) caused by partial receptor saturation for very large $q$. Therefore, variations in quantal size can account for most of the observed variability and skew in mini amplitude distributions, but the size and shape of the mini distributions depend on the degree of receptor satu- ration. Importantly, saturation levels did not depend on the size of the postsynaptic receptor pool. Variable-sized quanta $(n=$ 1000) with $\bar{q}=2000$ were released at synapses containing 50 (Fig. 6A), 200 (Fig. $6 B$ ), or 800 (Fig. 6C) AMPARs. Note that the variability, skewness, and saturation levels were primarily insensitive to the number of receptors on the postsynaptic membrane.

\section{Dependence on release location}

We next examined the degree to which transmitter release from different spatially distinct sites above the PSD contributes to the total variability. To isolate RLD, $q$ was fixed at 2000, and we considered only the ensemble averages (100 trials per release site), thus eliminating channel noise. Figure $7 A$ shows the results for seven of these locations. Note that the release from the center of the active zone was most efficacious, and that efficacy decreased with increasing distance from the center. Figure $7 B$ shows the distribution of amplitudes for the ensemble averages from 51 different release locations (release from the center of the active zone and 50 randomly assigned locations; CV, 0.29; skewness, $-0.03)$. Open probabilities $\left(P_{\text {open }}\right)$ were calculated for a single receptor located different distances from the release site. Release immediately above the receptor cluster was most efficacious and decreased dramatically with increasingly misaligned release events (Fig. 7C). Receptors were essentially unaffected by release events $>300 \mathrm{~nm}$ away, and the signal-to-noise ratio decreased catastrophically as $P_{\text {open }}$ decreased. (Receptors $>300 \mathrm{~nm}$ from the release site had CVs of $>2$.) Note that this effect depends on the tangential diffusion constant of glutamate, and RLD would be greater if the cleft was anisotropic.

To further demonstrate the RLD, we rendered snapshots of two simulations with a release from either the center (Fig. $8 A$ ) or edge (Fig. $8 \mathrm{~B}$ ) of the active zone. Figure $8 \mathrm{Aa}$ plots the evolution of single- and double-bound AMPAR states after central release for a single trial. (Double-bound states include the double-bound closed state and the open conducting state.) Figure $8, A b-A d$, shows these data at 1,40 , and $250 \mu \mathrm{sec}$ after release. The observer is looking down on the top of the PSD through the presynaptic bouton and the synaptic cleft. After release, glutamate rapidly diffused across and out of the cleft. With central release events, the number of double-bound receptors increased most steeply 40 $\mu \mathrm{sec}$ after release $(20-80 \%$ rise time, $40 \mu \mathrm{sec})$, by which time glutamate had equilibrated across the synapse (Fig. $8 \mathrm{Ac}$ ). By the time the number of double-bound receptors had peaked (250 $\mu \mathrm{sec}$ after release), synaptic glutamate concentration had dropped dramatically, precluding additional receptor activation, and double-bound AMPARs were distributed approximately equally across the PSD (Fig. $8 \mathrm{Ad}$ ).

Fewer receptors were double-bound (75\%) and the rise-time was slower $(139 \mu \mathrm{sec})$ when a transmitter was released from the 

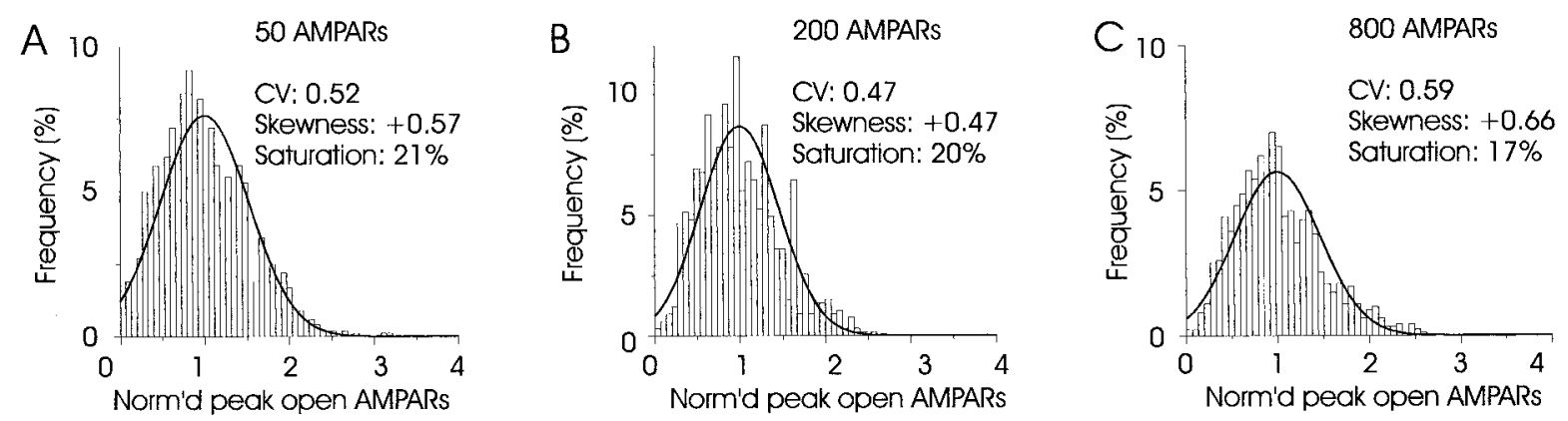

Figure 6. The shape of mini amplitude distributions does not depend on receptor number. $A-C$, Normalized distribution of mini amplitude after release at synapses containing $50(A), 200$ ( $B$ ), and 800 (C) AMPARs after release with variable $q$. Solid lines indicate the shape of the forced Gaussian distribution using the mean and SD of the mini distribution. Data in $B$ are the same as shown in Figure $3 B$ but normalized to a mean amplitude of 1 . Note that the shape, variability, and saturation levels were similar at synapses with a large range of receptors.

edge of the PSD (Fig. $8 \mathrm{Ba}$ ). A gradient of transmitter still extended across the synapse $40 \mu \mathrm{sec}$ after release, with little glutamate in the synaptic quadrant opposite release and doublebound receptors restricted to the regions of the PSD proximal to the release location (Fig. $8 \mathrm{Bc}$ ). After $250 \mu \mathrm{sec}$, the synaptic glutamate concentration was significantly reduced and most of the double-bound receptors were proximal to the release location (Fig. $8 B d$ ). To summarize, different release sites on the active zone have different potencies according to their eccentricity and can therefore add a significant amount of variability to both amplitude and rise-time distributions.

\section{Signaling at different-shaped PSDs}

Although PSD size and shape vary considerably, active zone and PSD areas are closely aligned across synapses (Schikorski and Stevens, 1997). It has also been suggested that AMPARs are distributed in an outer ring around NMDARs, which are clustered in the middle of the PSD (Kharazia and Weinberg, 1997, 1999), and that PSDs $<180 \mathrm{~nm}$ in diameter lack AMPARs (Takumi et al., 1999). To explicitly test the effect of variations in the size and shape of the PSD/active-zone complex or the distribution of postsynaptic receptors across the PSD, we examined the activation of AMPARs using three other PSD/active-zone geometries: a small, round, 200-nm-diameter PSD; a $100 \times 314 \mathrm{~nm}$ rectangular PSD; and a larger round PSD with AMPARs restricted to an outer annulus (inner diameter, $180 \mathrm{~nm}$; outer diameter, $270 \mathrm{~nm}$ ) (Fig. 9A) [Schikorski and Stevens (1997), their Fig. 5]. These geometries were selected such that receptor densities on all three PSD areas were equal. In all cases, the active zone extended over the area of the spine occupied by the PSD, with 20 randomly assigned release locations on each active zone, and quantal size was held constant at 2000. For the annular PSD, the active zone extended over both the inner receptor-free and outer receptorpopulated regions of the annulus. Because their distribution across the active zone was uniform, the mean location of all release sites was still the center of the active zone.

The distances measured from the center of the release plane to the mean receptor displacement on the PSD ( $\Delta \bar{x}$ values) were as follows: $200 \mathrm{~nm}$ disk PSD, $71 \mathrm{~nm}$; rectangular PSD, $86 \mathrm{~nm}$; annular PSD, $229 \mathrm{~nm}$. These correspond to the average efficacies $(n=400)$ of the synapses: $200 \mathrm{~nm}$ disk PSD $\left(P_{\text {open }}, 0.20\right)>$ rectangular PSD $\left(P_{\text {open }}, 0.16\right)>$ annular PSD $\left(P_{\text {open }}, 0.14\right)$ (Fig. $9 B)$. Note that the efficacy of the small disk PSD was greater than the less densely populated 350-nm-diameter PSD used previously in the model with the same number of receptors $\left(P_{\text {open }}\right.$, 0.093), in which $\Delta \bar{x}$ was $124 \mathrm{~nm}$. RLD was lowest at the annular PSD, slightly larger with the 200-nm-diameter PSD, and largest
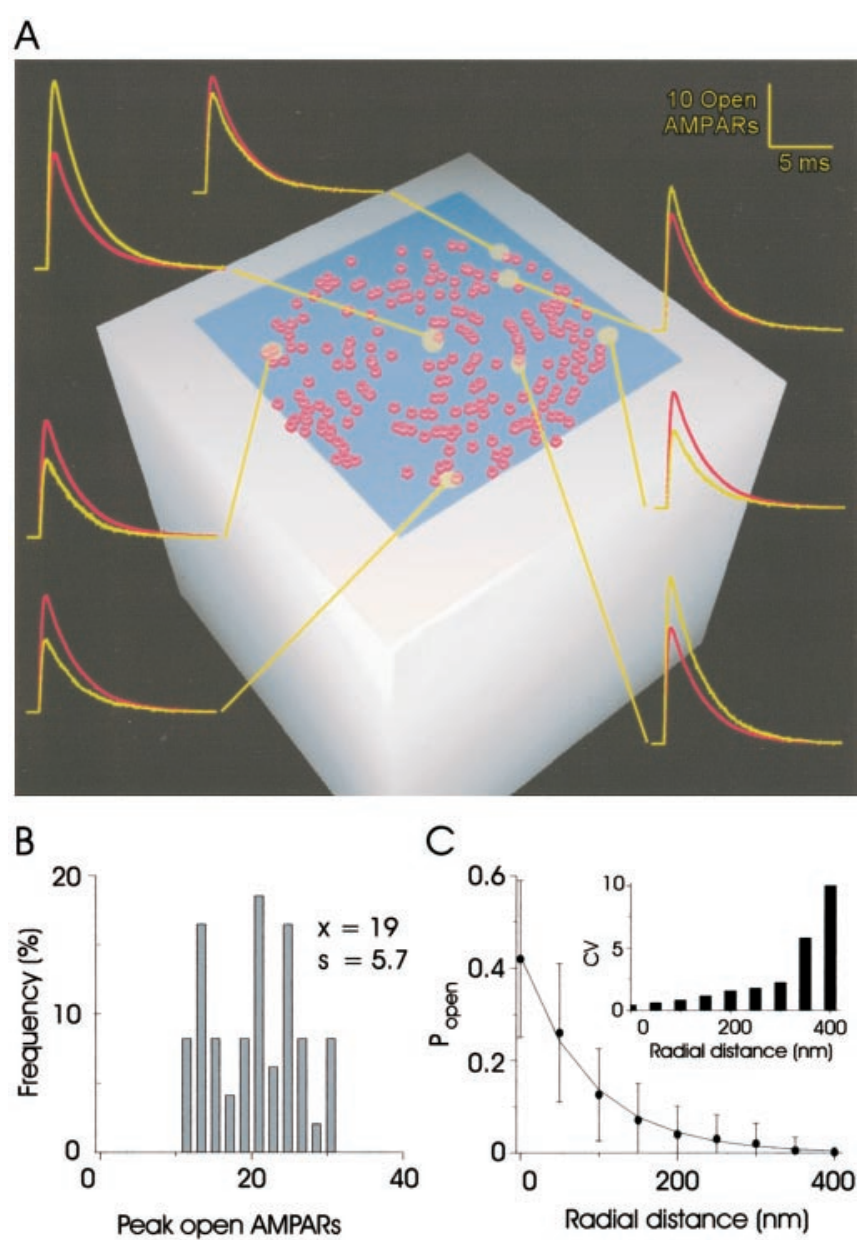

Figure 7. Synaptic efficacy depends on release location. $A$, Schematic representation of the synaptic cleft. Individual AMPARs (red) were distributed across a $350 \mathrm{~nm}$ disk atop the spine (gray). Release sites were distributed across a flat active zone $350 \mathrm{~nm}$ on a side (blue) adjacent to the underside of the presynaptic bouton (data not shown). Yellow traces represent the ensemble average of simulations released from a single point, whose location is indicated by the yellow disks. Each trace is plotted with the ensemble average from all locations (red traces) for comparison with relative efficacy. $B$, Distribution of all peak open AMPARs from ensemble averages 51 release locations (release from the center, 50 randomly assigned locations). $C$, Decreasing average probability of activating individual receptors displaced with increasing radial distance from the site of release. The solid line is an exponential fit to the data; $P_{\text {open }}=$ $0.42 \times e^{-r / 88 \mathrm{~nm}}$, where $r$ is the radial distance from the center of the PSD. NMDAR efficacy displayed similar spatially dependent properties, with an e-fold decrement of $\sim 125 \mathrm{~nm}$ (data not shown). Inset, CV increased with increasing radial distance from the site of release. 
Aa

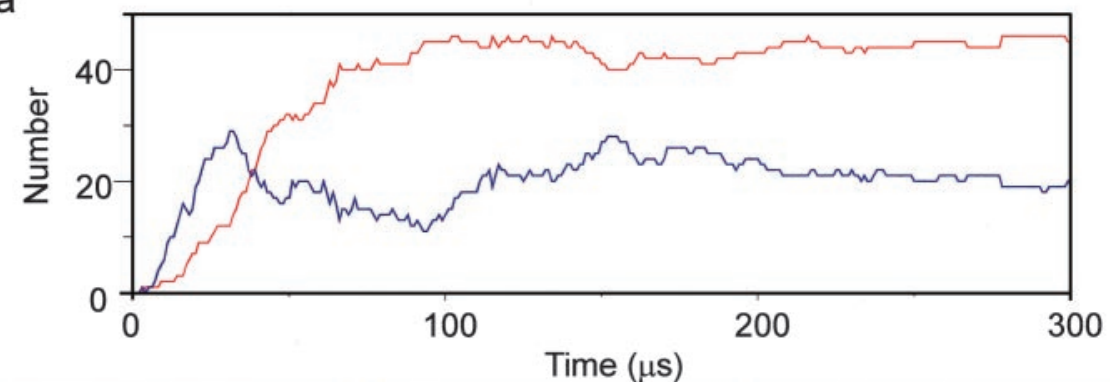

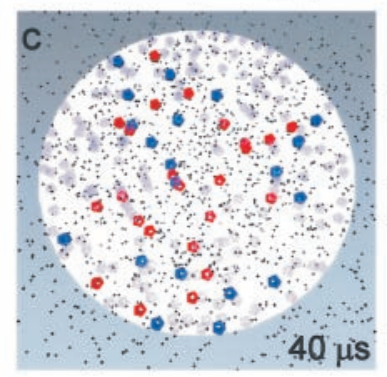

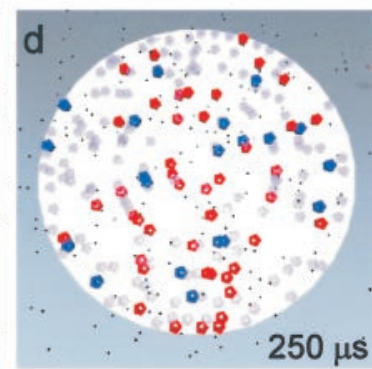

$\mathrm{Ba}$
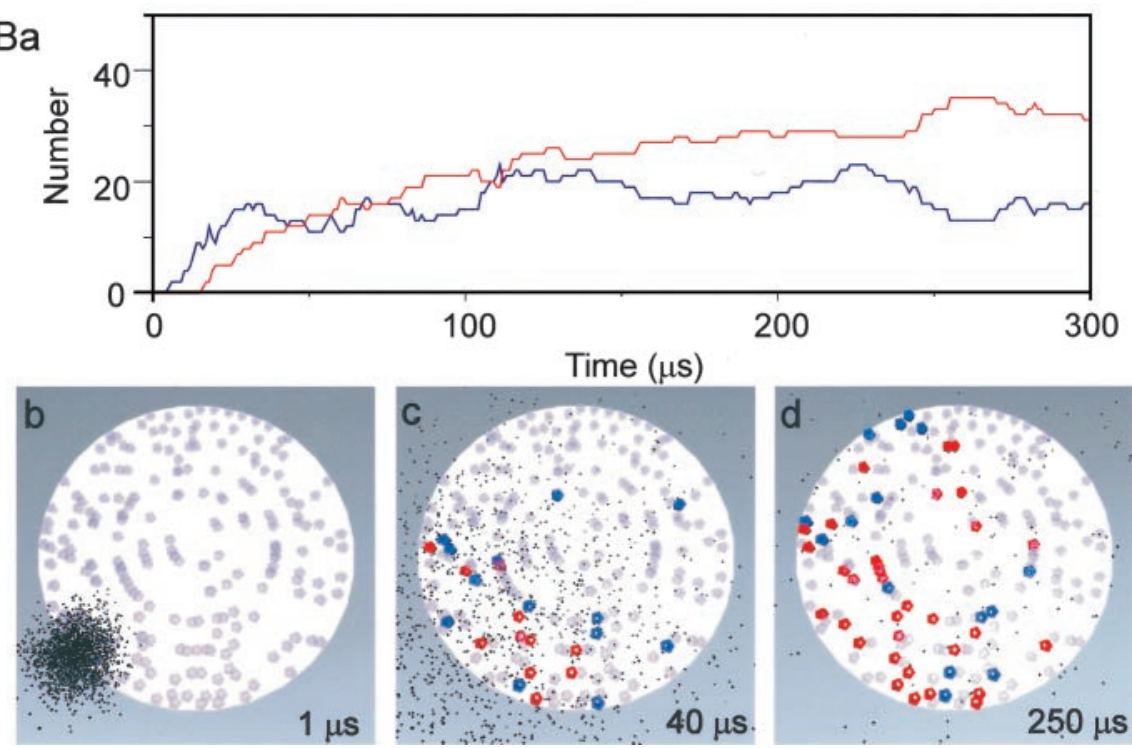

Figure 8. Differences in receptor activation with central and peripheral release events. $A$, Release from the center of the synapse. $a$, Evolution of single-bound (dark blue) and double-bound (red) AMPAR states with release at $t=0 . b$, Schematic showing the synaptic cleft and synaptic face of the postsynaptic cell $1 \mu$ sec after release. Glutamate is indicated by small black spheres. The white disk shows 350-nm-diameter PSD. AMPARs are 60-nm-diameter pentagonal structures with state-dependent color coding: single-bound, darkblue; double-bound, red; all other receptor states, including unbound and desensitized, light blue. c, Forty microseconds after release, the transmitter had equilibrated across the synapse and the number of double-bound receptors increased most steeply. $d$, By $250 \mu$ sec, most of the transmitter had left the cleft, and the number of double-bound receptors, distributed uniformly across the synapse, had peaked. $B$, Release from the edge of the synapse. $a$, Evolution of single- and double-bound AMPARs states. $b$, Glutamate distribution $1 \mu$ sec after release from the edge of synapse. $c$, One-half of the transmitter had left the cleft, although its distribution was not yet uniform after $40 \mu \mathrm{sec}$. Primarily receptors near the release site were bound. $d$, Significantly fewer AMPARs, primarily those close to the release site, were double-bound $250 \mu$ sec after peripheral release.

with the rectangular PSD (Fig. 9C). Moreover, the distribution of ensemble averages at the 200-nm-diameter PSD was less variable $(\mathrm{CV}, 0.094)$ than the 350-nm-diameter PSD. This was expected for more clustered PSD/active-zone complexes given that RLD depends on variable diffusion distances from release sites to the receptor population. The difference between mean diffusion path-lengths for each release site at the annular PSD and either the rectangular PSD or the $350-\mathrm{nm}$ diameter PSD was smaller, because release sites above the inner ring of the PSD all have similar $\Delta \bar{x}$ values, and thus explain the low $\mathrm{CV}$ at the annular PSD. CV at the rectangular PSD was highest with randomly assigned release locations with little difference between release sites distributed along the short axis, but there were large differences between those distributed along the long axis (data not shown). In conclusion, the geometry of and receptor distribution on the synapse are important determinants of the shape of mini amplitude distribution.

\section{Noise sources are independent}

The variability from the three different sources should be independent, and summing the variances measured for each source should equal the variance measured with all sources of variability (i.e., the variability measured in Fig. $2 B$ ). Variability in $q$ could not be separated from channel noise, and the variance measured from the raw RLD data (as opposed to the ensemble averages) also contained the variance from channel noise; thus, if the three sources of variance were independent then,

$$
C V_{\text {Total }}^{2}=C V_{\mathrm{q}}^{2}+C V_{\text {location }}^{2}-C V_{\text {channel }}^{2}
$$

$C V_{\mathrm{q}}^{2}$ is the normalized variance attributable to $\Delta q$ with release from a fixed location, $C V_{\text {location }}^{2}$ is the normalized variance of the responses measured from all release locations but with fixed $q$, and $C V_{\text {channel }}^{2}$ is the normalized variance caused by channel noise, in which both release location and $q$ were fixed. For these simulations,

$$
\begin{array}{r}
(0.59)^{2} \approx(0.47)^{2}+(0.37)^{2}-(0.16)^{2} \\
=(0.58)^{2}, \quad(4)
\end{array}
$$

which is consistent with the independent contribution of all three sources to the total observed variance. Thus, for a $350-\mathrm{nm}$ diameter synapse with $\sim 200$ AMPARs and a mean quantal size of 2000 glutamate molecules, $58 \%$ of the variability was caused by variations in quantal size, $36 \%$ of the variability was caused by release from different sites on the active zone, and $8 \%$ of the variability was caused by channel noise.

\section{Discussion}

\section{Independent sources of variability}

Our model used three sources of synaptic variability to reproduce the distribution of mini amplitudes observed in experiments. These sources are channel noise, release from spatially distinct 
A
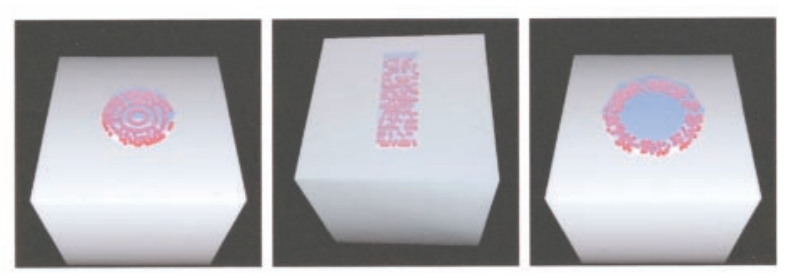

B

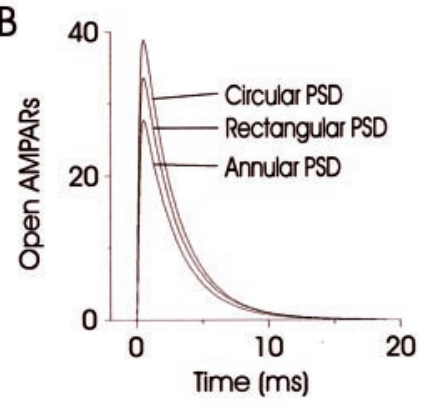

C

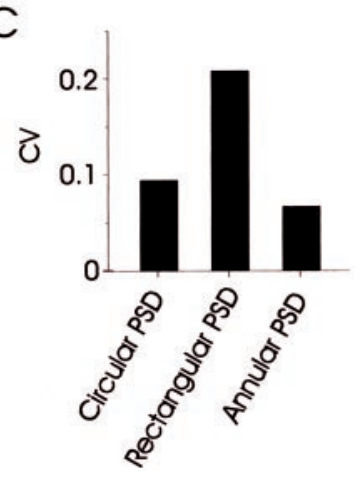

Figure 9. Signaling properties with different synaptic configurations. A, Schematic view of the three synaptic configurations that were used (from left to right): circular PSD, rectangular PSD, and annular PSD. Note that all PSD areas and receptor densities are the same. Twenty release locations were randomly assigned to the release plane (blue) located just below the presynaptic bouton. $B$, Ensemble averages ( $n=1000 ; 50$ trials from each location) for the three synaptic configurations. C, Release-location-dependent variability for the three synaptic configurations. The data shown are variability in the peak number of open receptors from the ensemble averages for each of the 20 release locations.

locations within the active zone, and variations in synaptic glutamate concentration. The major source of variability underlying channel noise was stochastic fluctuations of double-bound AMPARs between conducting and nonconducting states. Tang et al. (1994) found that cyclothiazide, which blocks desensitization, reduced the variability of the non-NMDA components of EPSCs. However, cyclothiazide also increases the glutamate affinity of the receptors leading to AMPAR saturation, which can explain the dramatic reduction in variability. Blocking desensitization in our model did not lead to a significant reduction in quantal variability, suggesting that the results obtained by Tang et al. (1994) were primarily caused by cyclothiazide-induced receptor saturation.

The largest source of variability at single synapses was caused by the release of variable amounts of transmitter. We assumed that the concentration of transmitter was constant across vesicle diameter, which is supported by genetic experiments with Drosophila in which there was a linear relationship between quantal size and vesicular volume (Karunanithi et al., 2002). Because variation in vesicle diameters produced a third-power variation in vesicle volume, and therefore $q$, a normal distribution of vesicle diameters produced a positively skewed distribution of open AMPARs that increased with the amount of jitter in vesicle diameter, but only when receptors were not saturated. These results are consistent with distributions of mini amplitudes measured at many single central glutamatergic synapses (Bekkers et al., 1990; Raastad et al., 1992; Liu and Tsien, 1995; Liu et al., 1999; McAllister and Stevens, 2000; Hanse and Gustafsson, 2001).

However, a clear understanding of the nature of quantal variability has proved elusive, because action potential-evoked synaptic currents at excitatory synapses have also produced Gaussian distributions (Bolshakov and Siegelbaum, 1995; Forti et al., 1997), and recently, both skewed and Gaussian distributions have

been reported at different synapses in the same preparation (Hanse and Gustafsson, 2001). An important advantage of our model is the ability to specify and isolate the sources of variability. In particular, action potential-evoked responses may have small signal-to-noise ratios in which the contamination of a nonGaussian signal with a large Gaussian noise component might give an appearance of a Gaussian signal. An alternative physiological explanation for Gaussian distributions may be caused by receptor saturation. Hanse and Gustafsson (2001) observed that the synapses that had low CVs tended to be of larger amplitude, more saturated, and have Gaussian distributions similar to those reported by Tang et al. (1994) and Forti et al. (1997), whereas those that had high CVs tended to have smaller mean amplitudes, be less saturated, and have highly skewed distributions.

What determines the degree of saturation at a given synapse? Simply, larger synapses with more receptors may be less saturated than smaller synapses with less receptors, but this argument is inconsistent for two reasons. First, previous modeling studies have shown that saturation levels depend primarily on quantal size and are primarily independent of the number of receptors (Faber et al., 1992; Holmes, 1995; Franks et al., 2002). Second, synapses with fewer receptors would be less potent and more variable, contrary to the results of Hanse and Gustafsson (2001). Alternatively, our simulations show that synapse-to-synapse variations in the mean glutamate concentration in vesicles can account for these observations. Specifically, we have shown that for vesicles with low transmitter concentrations, skewed distribution of vesicle volumes resulted in low potency, highly variable, and skewed distributions of responses. However, for high vesicle glutamate concentration, the activation of synaptic receptors by the tail of very large values in the skewed distribution of $q$ was compressed because of receptor saturation, resulting in response amplitudes with a low CV and a Gaussian distribution.

Interestingly, increasing vesicular transmitter concentration, either by overexpression of vesicle transporters at a cholinergic synapse (Song et al., 1997) or by increased loading of a transmitter into vesicles by raising cytoplasmic glutamate concentration (Ishikawa et al., 2002), resulted in increased mean receptor activation with narrower, less-skewed amplitude distributions. Evers et al. (1989) also observed that spontaneous synaptic currents at developing neuromuscular junctions were initially small with large skewed distributions, whereas more mature synapses showed larger synaptic currents whose distributions were less variable and more Gaussian. However, they were unable to determine whether this was attributable to differences in $q$ or the extent of close membrane apposition near the release sites. Thus, differences in either synaptic maturation or vesicle filling could explain the different distributions reported by Hanse and Gustafsson (2001) or the large Gaussian distributions reported by Forti et al. (1997). Note also that Forti et al. (1997) recorded from synapses with large elliptical presynaptic varicosities (longitudinal diameter, $1.67 \pm 0.60 \mu \mathrm{m})$, suggesting that these synapses contained multiple active zones (see below). Occasional simultaneous release of multiple vesicles from these large synapses would result in a large mean response with a high variance but a low $\mathrm{CV}$ and a Gaussian distribution.

\section{Implications of RLD}

Although the total active zone area per bouton is linearly related to the volume of the presynaptic bouton (Streichert and Sargent, 1989; Yeow and Peterson, 1991; Pierce and Mendell, 1993; Schikorski and Stevens, 1997), the size of individual active zones is typically $<0.2 \mu \mathrm{m}^{2}$ and almost never exceeds $0.4 \mu \mathrm{m}^{2}$ (Yeow 
and Peterson, 1991; Schikorski and Stevens, 1997). Larger boutons appear to produce multiple small active zones rather than a single large one, suggesting that larger active zones might not function optimally (Schikorski and Stevens, 1997). We found a dramatic decrease in both the activation and signal-to-noise ratio of receptors, located increasing distances from the release site, and that AMPARs $>300 \mathrm{~nm}$ from the release site were unable to reliably detect release events. These findings confirm a previous analysis of concentration gradients across the active zone (Uteshev and Pennefather, 1997). The more distant release leads to smaller peak concentrations of glutamate at the AMPARs, thus activating a smaller fraction of them. Thus, the small size and close association typical of the active zone/PSD complex (Schikorski and Stevens, 1997) suggest that most receptors are able to reliably detect release events from anywhere on the active zone.

The dynamic regulation of AMPARs has been proposed as a cellular mechanism to explain long-term synaptic plasticity (Malinow and Malenka, 2002), and surface expression of AMPARs at central spinous synapses is constrained to the PSD (Kharazia et al., 1996; Nusser et al., 1998; Takumi et al., 1999). This allows two methods for regulating receptor number: receptors can either be inserted or removed from predefined slots in a PSD of fixed size, thus changing receptor density, or the size of the PSD can shrink or expand to accommodate AMPAR removal or insertion, thus maintaining a fixed receptor density. The latter is consistent with electron microscopy studies (Nusser et al., 1998; Takumi et al., 1999) and the observation that bigger synapses produce bigger responses (Andrasfalvy and Magee, 2001; Matsuzaki et al., 2001). Our simulations predict that the density and spatial arrangement of receptors at the synapse are important determinants of receptor activation. Because release sites are distributed above the postsynaptic area on which receptors are located, smaller denser synapses will be more efficacious than larger ones with the same number of receptors. Synapse potency is linearly related to receptor density (Franks et al., 2002). However, for constant receptor density, increasing the receptor number requires increasing the synapse size, which decreases the average receptor efficiency for a given release event. Thus, a sublinear relationship describes receptor number and activation for constant receptor density and predicts a decrease in average receptor efficacy with receptor insertion.

Our results show that release events from the side of the active zone are less potent than those from the center. If the presynaptic $\mathrm{Ca}^{2+}$ sensor responsible for release is located very close to the $\mathrm{Ca}^{2+}$ channel(s) and/or mobile $\mathrm{Ca}^{2+}$ buffers sharply narrow the distribution of high $\mathrm{Ca}^{2+}$ (Sabatini et al., 2001), release locations should be independent. However, if $\mathrm{Ca}^{2+}$ enters the terminal from multiple channels distributed uniformly in the activerelease zone and the buffering is weak, the elevated $\mathrm{Ca}^{2+}$ merges at the central release sites, which have higher probabilities than peripheral ones. Thus, in stimulus trains designed to deplete storage pools, higher probability central release sites should release first, producing an average decrease in potency with increasing stimulus number. However, no change in average potency was seen under these conditions (Dobrunz and Stevens, 1997; Hanse and Gustaffson, 2002), suggesting that release sites were independent. There is evidence at the calyx of Held for multiple clusters of $\mathrm{Ca}^{2+}$ channels over a range of distances from the release sites of the vesicles (Meinrenken et al., 2002).

Minimal stimulation paradigms are designed to stimulate only one axon that makes contact with a postsynaptic cell at a single synapse. However, the synapse is likely to have $\sim 10$ docked vesicles that are presumably located at the position from which they can be released. Careful titration of Clostridium toxins could reduce the number of functional release sites until, ideally, a single docking site remains, and the distribution of evoked amplitudes could be measured under these conditions. RLD predicts that evoked PSCs under these conditions should be smaller than controls.

In conclusion, we have produced a biophysically realistic model of postsynaptic receptor activation at an idealized central glutamatergic synapse that reproduces experimentally observed variations in synaptic responses recorded from single glutamatergic synapses. Although our simulations demonstrate that the site of transmitter release can affect synaptic efficacy, we confirm that variations in synaptic glutamate concentration, arising from anatomically constrained measures of jitter in vesicle diameter, are sufficient to account for the majority of the observed variance and distribution skewness. However, some of the key assumptions underlying our results need to be tested; in particular, the variation of transmitter concentration among vesicles could also contribute to the observed variability in quantal amplitudes.

\section{References}

Andrasfalvy BK, Magee JC (2001) Distance-dependent increase in AMPA receptor number in the dendrites of adult hippocampal CA1 pyramidal neuron. J Neurosci 21:9151-9159.

Auger C, Marty A (1997) Heterogeneity of functional synaptic parameters among single release sites. Neuron 19:139-150.

Auger C, Marty A (2000) Quantal currents at single-site central synapses. J Physiol (Lond) 526:3-11.

Bartol Jr TM, Land BR, Salpeter EE, Salpeter MM (1991) Monte Carlo simulation of miniature endplate current generation in the vertebrate neuromuscular junction. J Biophys 59:1290-1307.

Bekkers JM, Richardson G, Stevens CF (1990) Origin of variability in quantal size in cultured hippocampal neurons and hippocampal slices. Proc Natl Acad Sci USA 87:5359-5362.

Bolshakov VY, Siegelbaum SA (1995) Regulation of hippocampal transmitter release during development and long-term potentiation. Science 269:1730-1734.

Bushong EA, Martone ME, Jones YZ, Ellisman MH (2002) Protoplasmic astrocytes in CA1 stratum radiatum occupy separate anatomical domains. J Neurosci 22:183-192.

Dobrunz LE, Stevens CF (1997) Heterogeneity of release probability, facilitation, and depletion at central synapses. Neuron 18:995-1008.

Evers J, Laser M, Sun YA, Xie ZP, Poo MM (1989) Studies of nerve-muscle interactions in Xenopus cell culture: analysis of early synaptic currents. J Neurosci 9:1523-1539.

Faber DS, Young WS, Legendre P, Korn H (1992) Intrinsic quantal variability stochastic properties of receptor-transmitter interactions. Science 258:1494-1498.

Forti L, Bossi M, Bergamaschi A, Villa A, Malgaroli A (1997) Loose-patch recordings of single quanta at individual hippocampal synapses. Nature 388:874-878.

Franks KM, Bartol Jr TM, Sejnowski TJ (2002) A Monte Carlo model reveals independent signaling at central glutamatergic synapses. Biophys J 83:2333-2348.

Frerking M, Borges S, Wilson M (1995) Variation in GABA mini amplitude is the consequence of variation in transmitter concentration. Neuron 15:885-895.

Geiger JRP, Roth A, Taskin B, Jonas P (1999) Glutamate-mediated synaptic excitation of cortical interneurons. In: Handbook of experimental pharmacology, Vol 141. Ionotropic glutamate receptors in the CNS (Jonas P, Monyer H, eds). Berlin: Springer.

Hanse E, Gustafsson B (2001) Quantal variability at glutamatergic synapses in area CA1 of the rat neonatal hippocampus. J Physiol (Lond) 531: 467-480.

Holmes WR (1995) Modeling the effect of glutamate diffusion and uptake on NMDA and non-NMDA receptor saturation. Biophys J 69:1734-1747.

Isaacson JS, Nicoll RA (1993) The uptake inhibitor L-trans-PDC enhances responses to glutamate but fails to alter the kinetics of excitatory synaptic currents in the hippocampus. J Neurophysiol 70:187-191. 
Ishikawa T, Sahara Y, Takahashi T (2002) A single packet of transmitter does not saturate postsynaptic glutamate receptors. Neuron 34:613-621.

Jonas P, Major G, Sakmann B (1993) Quantal components of unitary EPSCs at the mossy fibre synapse on CA3 pyramidal cells of rat hippocampus. J Physiol (Lond) 472:615-663.

Karunanithi S, Marin L, Wong K, Atwood HL (2002) Quantal size and variation determined by vesicle size in normal and mutant Drosophila glutamatergic synapses. J Neurosci 22:10267-10276.

Kharazia VN, Weinberg RJ (1997) Tangential synaptic distribution of NMDA and AMPA receptors in rat neocortex. Neurosci Lett 238:41-44.

Kharazia VN, Weinberg RJ (1999) Immunogold localization of AMPA and NMDA receptors in somatic sensory cortex of albino rat. J Comp Neurol 412:292-302.

Kharazia VN, Phend KD, Rustioni A, Weinberg RJ (1996) EM colocalization of AMPA and NMDA receptor subunits at synapses in rat cerebral cortex. Neurosci Lett 210:37-40.

Lehre KP, Danbolt NC (1998) The number of glutamate transporter subtype molecules at glutamatergic synapses: chemical and stereological quantification in young adult rat brain. J Neurosci 18:8751-8757.

Lester RA, Jahr CE (1992) NMDA channel behavior depends on agonist affinity. J Neurosci 12:635-643.

Liu G, Tsien RW (1995) Properties of synaptic transmission at single hippocampal synaptic boutons. Nature 375:404-408.

Liu G, Choi S, Tsien RW (1999) Variability of neurotransmitter concentration and nonsaturation of postsynaptic AMPA receptors at synapses in hippocampal cultures and slices. Neuron 22:395-409.

Mainen ZF, Malinow R, Svoboda K (1999) Synaptic calcium transients in single spines indicate that NMDA receptors are not saturated. Nature 399:151-155.

Malinow R, Malenka RC (2002) AMPA receptor trafficking and synaptic plasticity. Annu Rev Neurosci 25:103-126.

Matsuzaki M, Ellis-Davies GC, Nemoto T, Miyashita Y, Iino M, Kasai H (2001) Dendritic spine geometry is critical for AMPA receptor expression in hippocampal CA1 pyramidal neurons. Nat Neurosci 4:1086-1092.

McAllister AK, Stevens CF (2000) Nonsaturation of AMPA and NMDA receptors at hippocampal synapses. Proc Natl Acad Sci USA 97:6173-6178.

Meinrenken CJ, Borst JG, Sakmann B (2002) Calcium secretion coupling at calyx of Held governed by nonuniform channel-vesicle topography. J Neurosci 22:1648-1667.

Murthy VN, Schikorski T, Stevens CF, Zhu Y (2001) Inactivity produces increases in neurotransmitter release and synapse size. Neuron 32:673-682.

Nusser Z, Lujan R, Laube G, Roberts J, Molnar E, Somogyi P (1998) Cell type and pathway dependence of synaptic AMPA receptor number and variability in the hippocampus. Neuron 21:545-559.

Oertner TG, Sabatini BL, Nimchinsky EA, Svoboda K (2002) Facilitation at single synapses probed with optical quantal analysis. Nat Neurosci 5:657-664.

Pierce JP, Mendell LM (1993) Quantitative ultrastructure of Ia boutons in the ventral horn: scaling and positional relationships. J Neurosci 13:4748-4763.

Raastad M, Storm JF, Anderson P (1992) Putative single quantum and sin- gle fibre excitatory postsynaptic currents show similar amplitude range and variability in rat hippocampal slices. Eur J Neurosci 4:113-117.

Sabatini B, Maravall M, Svoboda K (2001) $\mathrm{Ca}^{2+}$ signaling in dendritic spines. Curr Opin Neurobiol 11:349-356.

Sarantis M, Balerini L, Miller B, Silver RA, Edwards M, Attwell D (1993) Glutamate uptake from the synaptic cleft does not shape the decay of the non-NMDA component of the synaptic current. Neuron 11:541-549.

Schikorski T, Stevens CF (1997) Quantitative ultrastructural analysis of hippocampal excitatory synapses. J Neurosci 17:5858-5867.

Schikorski T, Stevens CF (2001) Morphological correlates of functionally defined synaptic vesicle populations. Nat Neurosci 4:391-395.

Silver RA, Colquhoun D, Cull-Candy SG, Edmonds B (1996) Deactivation and desensitization of non-NMDA receptors in patches and the time course of EPSCs in rat cerebellar granule cells. J Physiol (Lond) 493:167-173.

Song H, Ming G, Fon E, Bellocchio E, Edwards RH, Poo MM (1997) Expression of a putative vesicular acetylcholine transporter facilitates quantal transmitter packaging. Neuron 18:815-826.

Stevens CF, Wang Y (1995) Facilitation and depression at single central synapses. Neuron 14:795-802.

Stiles JR, Bartol Jr TM (2001) Monte Carlo methods for simulating realistic synaptic microphysiology. In: Computational neuroscience: realistic modeling for experimentalists (de Schutter E, ed), pp 87-127. Boca Raton, FL: CRC.

Stiles JR, van Helden D, Bartol Jr TM, Salpeter EE, Salpeter MM (1996) Miniature endplate current rise times less than 100 microseconds from improved dual recordings can be modeled with passive acetylcholine diffusion from a synaptic vesicle. Proc Natl Acad Sci USA 93:5747-5752.

Stiles JS, Bartol Jr TM, Salpeter MM, Salpeter EE, Sejnowski TJ (2001) Synaptic variability: new insights from reconstructions and Monte Carlo simulations with MCell. In: Synapses (Cowan WM, Sudhof TC, Stevens CF, eds), pp 681-731. Baltimore: Johns Hopkins UP.

Streichert LC, Sargent PB (1989) Bouton ultrastructure and synaptic growth in a frog autonomic ganglion. J Comp Neurol 281:159-168.

Takahashi M, Sarantis M, Attwell D (1996) Postsynaptic glutamate uptake in rat cerebellar Purkinje cells. J Physiol (Lond) 497:523-530.

Takumi Y, Ramirez-Leon V, Laake P, Rinvik E, Ottersen OP (1999) Different modes of expression of AMPA and NMDA receptors in hippocampal synapses. Nat Neurosci 2:618-624.

Tang CM, Margulis M, Shi QY, Fielding A (1994) Saturation of postsynaptic glutamate receptors after quantal release of neurotransmitter. Neuron 13:1385-1394.

Uteshev VV, Pennefather PS (1996) A mathematical description of miniature postsynaptic current generation at central nervous system synapses. Biophys J 71:1256-1266.

Uteshev VV, Pennefather PS (1997) Analytical description of the activation of multi-state receptors by continuous neurotransmitter signals at brain synapses. Biophys J 72:1127-1134.

Yeow MB, Peterson EH (1991) Active zone organization and vesicle content scale with bouton size at a vertebrate central synapse. J Comp Neurol 307:475-486. 